\title{
Implementing the New ISO/IEC 29110 Systems Engineering Process Standard in a Small Public Transportation Company
}

\author{
Claude Y. Laporte ${ }^{1}$, Nicolas Tremblay ${ }^{1}$, Jamil Menaceur ${ }^{2}$, Denis Poliquin ${ }^{2}$ \\ ${ }^{1}$ École de technologie supérieure, Montréal, Canada \\ ${ }^{2}$ CSiT, Montréal, Canada \\ Claude.Y.Laporte@etsmtl.ca, nicolas.tremblay.9@ens.etsmtl.ca, \\ jamil.menaceur@csintrans.com, den-is.poliquin@csintrans.com
}

\begin{abstract}
The recently published ISO/IEC 29110 for systems engineering has been used as the main framework for the development of the management and systems engineering processes at CSinTrans Inc. (CSiT), a Canadian company, founded in 2011. CSiT specializes in the integration of communication and security systems in transit industry such as trains, subways and buses as well as railway stations, subway stations and bus stops. CSiT approved an internal project to define and implement project management and systems engineering processes. The project's history, purpose and rationale that prompted CSiT to adopt the new systems engineering process standard are presented. The implementation of the ISO/IEC 29110 is described. The reflections and decisions made during the implementation are presented. Recommendations and advice for organizations wanting to implement ISO/IEC 29110 are described. ISO/IEC 29110 has helped raise the maturity of the young organization by implementing proven practices and developing consistent work products from one project to another. ISO/IEC 29110 was a good starting point to align processes of CSiT with practices of CMMI ${ }^{\circledR}$. ISO/IEC 29110 has helped CSiT with developing light processes as well as remaining flexible and quick in its ability to respond to its customers.
\end{abstract}

Keywords. Very Small Entities, VSEs, ISO/IEC 29110, Systems Engineering, Process, Standards.

\section{INTRODUCTION}

CSiT is a Canadian company, established in 2011 in Montreal, specializing in the integration of inter-active systems, communication and security in the domain of public transport such as trains, subways and buses and railway stations, stations and stops Bus. In transit industry, customers often require a CMMI ${ }^{\circledR}[1]$ maturity level from suppliers such as CSiT. An independent evaluation confirming a CMMI ${ }^{\circledR}$ maturity level 2 increases the opportunity of winning con-tracts. Similarly, to ensure better work coordination and reduce risks, customers in this industry prefer working with mature suppliers in order to get timely quality products and within the agreed budget.

\section{ISO/IEC 29110 Software and Systems Engineering Standards and Guides}

As defined in ISO/IEC 29110 (ISO 29110 hereon), a Very Small Entity (VSE) is a company, an organization (e.g. government, not-for profit), a department or a project having up to 25 people [2]. VSEs can play different roles in systems engineering: either as suppliers or integrators, and sometimes both. Since most large organizations are structured in a way to be more manageable (e.g. project, department), VSEs are present at all stages of a product manufacturing chain.

A four-stage roadmap, called ISO 29110 profiles, has been developed for VSEs that do not develop critical systems or critical software: Entry, Basic, Intermediate and Advanced profiles. VSEs targeted by the Entry profile are those working on small projects (e.g., at most six person-months of effort) and for start-ups. The Basic profile describes the development practices of a single application by a single project team. The Intermediate profile is targeted at VSEs developing multiple 
projects with more than one team. The Advanced profile is targeted at VSEs wishing to sustain and grow as independent competitive businesses.

ISO 29110 has been successfully implemented in VSEs developing software (SW) in many countries [3]. ISO 29110 has been implemented, amongst others, in IT start-ups in Canada [4], in Peru [5] and in a VSE co-located in Tunisia and in Canada [6], in a large financial institution [7] and in a large utility provider [8]. VSEs that have implemented ISO 29110 management and engineering guides have improved one or more aspects of competitiveness (e.g. quality, cost, schedule). As an example, projects using ISO 29110 for the first time had only $10 \%$ to $18 \%$ of rework. A Canadian division of a large American engineering company has developed and implemented project management processes for their small-scale and medium-scale projects. The engineering organization used the Entry and Basic profiles of ISO 29110 for the development of their small and medium scale project management processes. An analysis of the cost and the benefits of the implementation of their small and medium scale project management processes was performed using an ISO economic benefits of standard method-ology. The engineering enterprise estimated that, over a three-year timeframe, savings of about 780,000CA\$ would be realized due to the implementation of project management processes using ISO 29110 [9], [10].

Systems, in the context of ISO/IEC 29110, are typically composed of hardware and software components. The systems engineering (SE) ISO 29110 has been developed using, as its main frameworks, the SW ISO 29110 [11] and ISO/IEC/IEEE 15288 [12]. With some exceptions, document descriptions are based on ISO/IEC/IEEE 15289 [13]. The SE Basic profile, as illustrated in figure 1, is composed of two processes: Project Management (PM) and System Definition and Realization (SR) [14]. An acquirer (i.e. a customer) provides a Statement of Work as an input to the PM process and receives a product as a result of SR process execution.

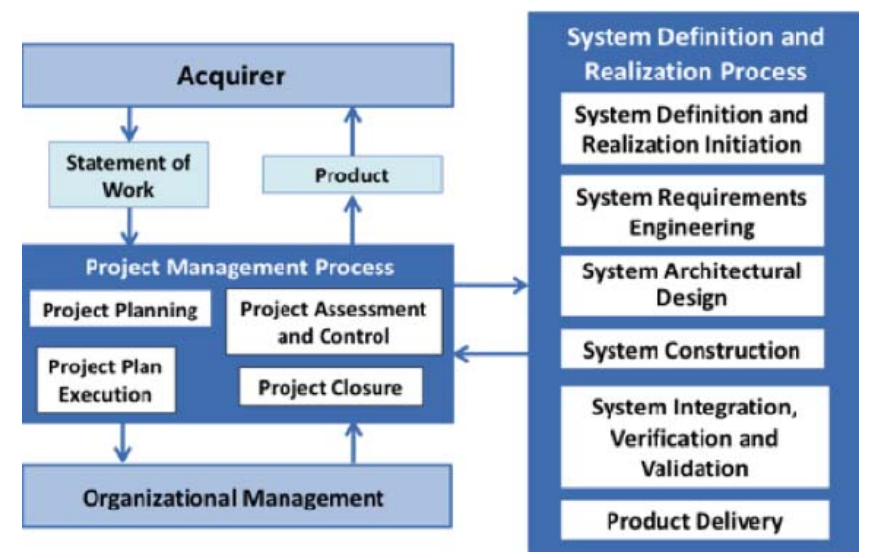

Fig. 1. Processes and activities of the ISO 29110 systems engineering Basic profile [14]

The SE ISO 29110 standard and guides are designed to work hand-in-hand with the SW ISO 29110 guides. ISO 29110 does not impose a specific life cycle model, therefore leaving VSEs free to choose the model that best suits their needs among the cascade, iterative, incremental, evolutionary and agile models. Similarly, ISO 29110 does not impose a specific method to its users [15].

Beside the published SW Entry and Basic profiles, the SE Entry profile [16] and the SE Basic profile [14] have been published. The SE Intermediate profile development should be completed in 2016 and published in 2017. The SE Advanced profile development should start in 2017 and should be published in 2018. The SE Basic profile guide is freely available in English and French from ISO. The German chapter of INCOSE (International Council on Systems Engineering), GfSE (Gesellschaft für Systems Engineering e.V.), has sponsored the translation of the systems engineering Basic profile. The German standard organization DIN (Deutsches Institut für Normung) should publish in 2017 the Basic profile in its catalogue. Finally, a translation in Arabic is led by a member of (International Council on Systems Engineering) INCOSE. 


\section{Motivations and objectives of the implementation of ISO 29110 at CSiT}

Shortly after its creation in 2011, CSiT learned that an event in Montréal would be held on the new ISO 29110 management and engineering guide for systems engineering. This standard was seen as a good starting point towards implementing CMMI level 2. Thus, CSiT has undertaken a new project to implement the ISO 29110 standard to guide the project management and system development activities. The Intermediate profile was targeted as it applies to VSEs that conduct several projects simultaneously with more than one team. However, the Basic profile was selected since the Intermediate profile was not published when the project was initiated at CSiT.

\subsection{Motivations for the implementation of project management and engineering processes}

Several factors prompted CSiT to develop and document their processes. Their first projects were based on employees' experience as well as recognized practices. This approach was effective and agile, but it was not possible to produce consistent deliverables from one project to another and be able to demonstrate that the work could be done over again since these practices were not documented into company's processes. Also, since there were no templates or checklists, project management and product development activities were done rather informally. Finally, considering business and nature of projects of CSiT, customers often require proof demonstrating rigorous work and a level of maturity.

The company considered the development and implementation of processes as a need, in other words the situation could become problematic if no action was taken. Specifically, the lack of a CMMI maturity level or compliance with international standards, such as ISO 29110, was not an option. CSiT wanted to ensure the company's growth and show its expertise and organizational maturity to its customers.

\section{Guidance for the implementation project}

To avoid making the process cumbersome and producing too many documents, participants gave themselves 2 sets of guidelines:

- For processes, the guideline was to add tasks not described in the SE Basic profile

- if they bring value to the context and projects of the company

- If they provide an alignment with CMMI level 2.

- For document templates, the guidelines were:

- Group different documents into one where possible;

- Each template's section must be relevant and applicable. If a section does not provide added value, it should not be included.

\section{Approach to the Implementation of the SE ISO 29110 at CSiT}

The first phase of the improvement project was to determine the set of documents to be produced during a typical project and how they should be organized in the document structure of the company. The five types of documents (i.e. policy, process, procedure, standard, support material) at the foundation of the company's quality system are illustrated in Figure 2.

For the moment, CSiT decided to leave aside the creation of training material because this material can take time to develop and does not really bring value at this time. The company prefers to promote interactive training in person rather than the reading of a document or the viewing of a presentation. Documented processes of the company can be used as training material for new employees. 


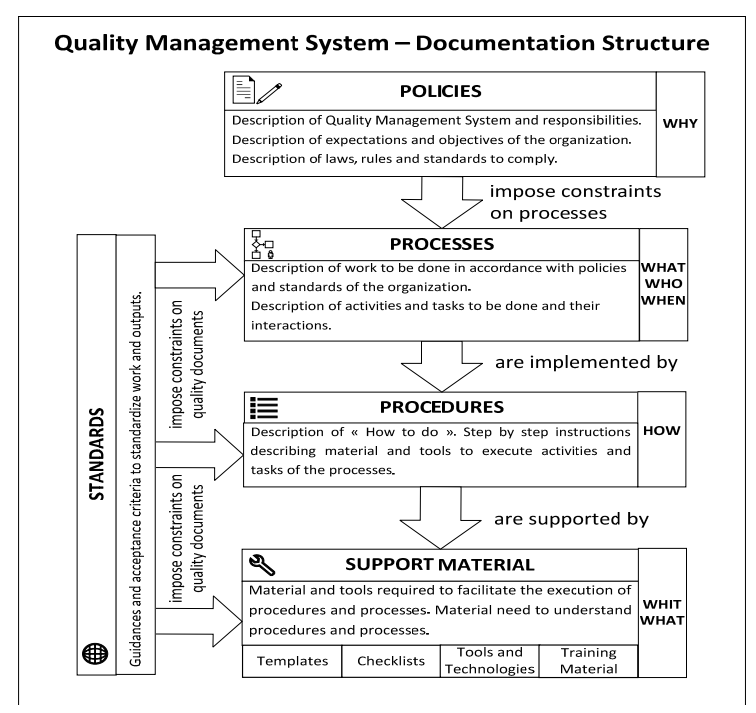

Fig. 2. Identification of documents and their relationships

\subsection{Processes and procedures description}

To better respond to different types of projects, CSiT decided to develop three process groups (i.e. light, standard, full), each being adapted to meet the attributes of projects such as the size and nature. Table 1 shows the three process groups and the frameworks to be used as reference.

\begin{tabular}{|c|c|c|c|}
\hline & Light Process & Standard Process & Full Process \\
\hline Type of project & $\begin{array}{l}\text { Proof of Concept, Pro- } \\
\text { totype } \\
\text { Concept validation or } \\
\text { Product Deployment at } \\
\text { Customer Site } \\
\text { Small Project }\end{array}$ & $\begin{array}{l}\text { Typical Project } \\
\text { Product intended to be } \\
\text { installed at Customer } \\
\text { Site } \\
\text { Medium Project }\end{array}$ & $\begin{array}{l}\text { Project when CMMI } \\
\text { level } 2 \text { is required by } \\
\text { a Customer } \\
\text { Product intended to be } \\
\text { installed at Customer } \\
\text { site } \\
\text { Large Project }\end{array}$ \\
\hline $\begin{array}{l}\text { Framework to be } \\
\text { used }\end{array}$ & $\begin{array}{l}\text { ISO/IEC TR } \\
\text { 6-1 - Entry profile } \\
+ \\
\text { CMMI - } \\
\begin{array}{l}\text { Agreement } \\
\text { ment }\end{array}\end{array}$ & $\begin{array}{l}\text { ISO/IEC TR } 29110-5-6- \\
2 \text { - Basic profile } \\
+ \\
\text { CMMI - } \quad \text { Supplier } \\
\text { Agreement Management }\end{array}$ & CMMI (Level 2) \\
\hline
\end{tabular}

Table 1. Classification of CSiT processes

\subsection{Using the management and engineering guide of ISO 29110}

To document CSiT processes, the management and engineering guide of ISO 29110 SE Basic profile was used as the main reference. The SW management and engineering guide of ISO 29110 Basic profile was also used as a reference to 
complement the SE guide. The SW guide was used to document processes involving the development of SW elements of a system. It is during the execution of the System Construction activity of the SE Basic profile that software components are developed. Then, in the next activity, as illustrated in Figure 1, hardware and software components are integrated.

\subsection{Using deployment packages}

Members of the INCOSE VSE working group have created Deployment Packages (DPs) to facilitate the adoption and implementation of ISO 29110 [17]. These free resources, available on Internet, have been used to support the documentation of CSiT processes. Figure 3 shows the SE set of DPs.

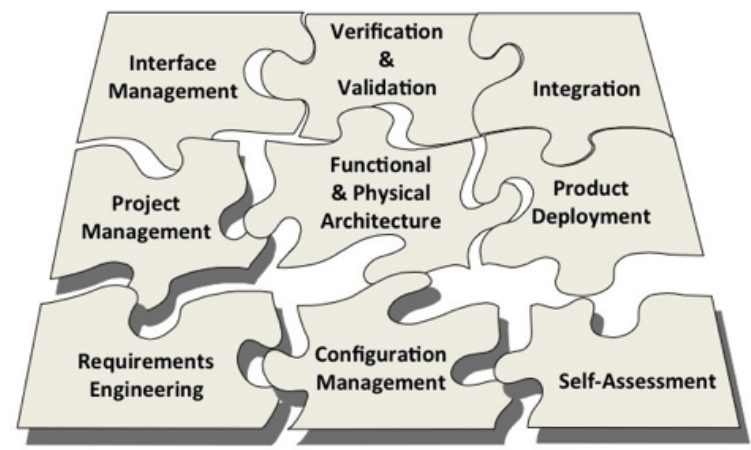

Fig. 3. Deployment packages to support the SE Basic profile

\subsection{Process documentation}

For the description of processes, CSiT decided to break down processes into activities and tasks. There are two reasons for this representation. First, this representation is simple and it is commonly used in industry and literature. Second, it is consistent with ISO 29110, which is structured the same way.

It was decided that documentation of CSiT processes would consist of two parts: a graphical part and a textual part. Each of these parts has different but complementary goals. The graphical part is primarily targeted at "experts", while the textual part is targeted mainly at "beginners" (e.g. a new employee) or an intermediate user (e.g. an employee who has participated to an engineering project) [18], [19].

The ETVX notation (i.e. Entry-Task-Validation-eXit) was developed in the 80s by IBM [20]. Given its simplicity of use, this notation has been adopted by many organizations. The template for the graphical description of the activities and tasks is shown in Figure 4. The textual part is a detailed description of activities, tasks and interactions between the activities of a process. The textual part describes the tasks, i.e. what to do, and the roles associated with each task. 


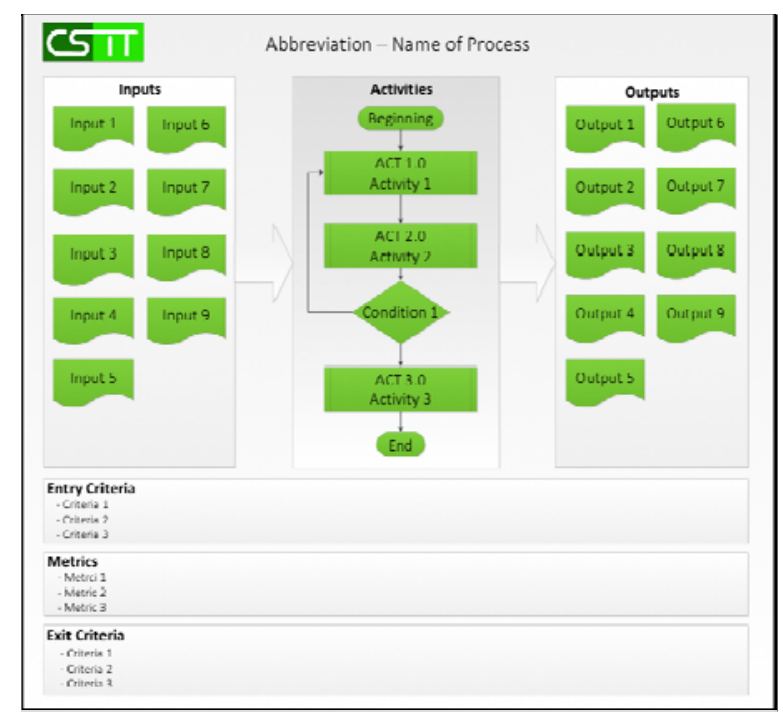

Fig. 4. Template for the graphical part of an activity

At CSiT, the format used to describe the activities is the notation used in the DPs of ISO 29110. Some adjustments were made to add a few attributes, such as measures to collect, entry criteria and exit criteria.

\subsection{Techniques Used to Help Defining and Implementing ISO 29110}

The Basic profile presents the project management and development processes using a waterfall lifecycle to simplify its understanding. However, the ISO 29110 guide indicates that it does not require the waterfall lifecycle, leaving VSEs to use the lifecycle that best suits their needs. Thus, CSiT decided to develop their own lifecycle models: a project lifecycle and a system development lifecycle. The definition of these lifecycle models have facilitated the description of the processes because they provided a clear understanding of when the processes need to be executed. In addition, the lifecycles have shown the importance of some processes that are not mentioned in the standard, but that must be used during the execution of projects. For example, it is possible that the company has to perform validation tests on the customer' site, to get the final acceptance of the system. For CSiT, this type of work is essential and was documented as a separate process.

\subsection{Identification of verification, validation and acceptance activities applicable to work products}

An important decision, made during the development of CSiT's processes, was to determine the types of peer review activities to be applied to the various work products of a project. ISO 29110 states that verifications of work products must be made, but without specifying the type. This leaves VSEs free to decide what best verification method applies to their context. For each deliverable, a decision was made for the adequacy or the need to perform at least one type of peer review. Four types of reviews were selected: personal review, desk-check, walkthrough and inspection.

For each review, the output documents have been defined. The four types of document are: a document review report, an annotated document, minutes of meeting and a completed checklist. Table 2 illustrates an example of the type of verification, validation and acceptance activities selected for the System Requirement Specification.

ISO 29110 defines the roles needed to produce and review the project deliverables (documentation and product components), but it does not define the roles of the people who must approve and/or sign deliverables before they are sent to a customer, a supplier or other external stakeholders. The right side of Table 2 indicates, for each deliverable, whether or not an internal approval is needed, whether or not it should be sent to the customer and whether or not a customer approval is required. If needed, the table could easily be tailored to meet the needs of a specific project. 


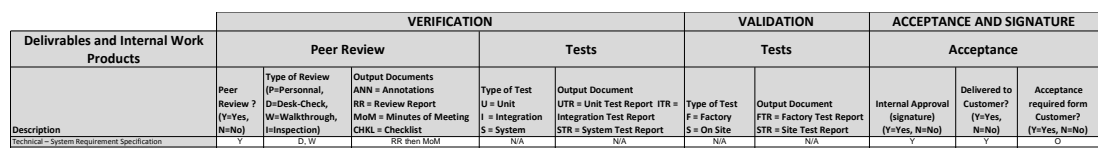

Table 2. Subset of the verification, validation and acceptance activities

\subsection{Selection of measures}

The ISO 29110 management and engineering guide lists the tasks associated to the collection and use of measures (e.g. resource, cost, time). The Basic profile does not detail how to collect and analyze the measures. The Intermediate and Advanced profiles will provide more details about the collection, analysis and utilisation of measures. The selection of measures was based on two principles: 1) a measure must meet a company's needs for information and, 2) a measure must be easy to collect and analyze. A subset of the measures selected is described in Table 3.

\begin{tabular}{|c|c|c|}
\hline Measure ID & Measures & Reasons \\
\hline MET-01 & $\begin{array}{l}\text { Number of errors detected by document type } \\
\text { and by phase of the development cycle }\end{array}$ & $\begin{array}{l}\text { To know the overall qual- } \\
\text { ity of each work product }\end{array}$ \\
\hline MET-02 & $\begin{array}{l}\text { Number of hours worked for each phase of the } \\
\text { system development cycle }\end{array}$ & \multirow{3}{*}{$\begin{array}{l}\text { To be able to use the per- } \\
\text { formance of past projects } \\
\text { to estimate new projects }\end{array}$} \\
\hline MET-03 & The cost of each project & \\
\hline MET-04 & $\begin{array}{l}\text { The attributes of each project: } \\
\text { - } \quad \text { Number of change requests; } \\
\text { - } \quad \text { Level of risk; } \\
\text { - } \quad \text { Predominance hardware/software. }\end{array}$ & \\
\hline MET-05 & $\begin{array}{l}\text { Distribution of effort related to the production, } \\
\text { review and correction of deliverables }\end{array}$ & $\begin{array}{l}\text { To be able to analyze the } \\
\text { efficiency of processes on } \\
\text { product quality }\end{array}$ \\
\hline MET-06 & $\begin{array}{l}\text { Resources spent versus those that were planned } \\
\text { in the project plan }\end{array}$ & $\begin{array}{l}\text { To be able to analyze if } \\
\text { the project is successful, } \\
\text { to identify gaps and take } \\
\text { the necessary remedial } \\
\text { action }\end{array}$ \\
\hline
\end{tabular}

Table 3. Subset of process and product measures

An electronic time sheet has been established to record the number of hours worked on each work product of a project. The timesheet allows to classify efforts in 3 categories: 1) efforts spent on the initial production of a work product; 2) efforts spent on reviewing it; 3 ) efforts spent on correcting identified defects. This data provides valuable information when improving a process or a work product. 


\subsection{Traceability between work products}

ISO 29110 includes tasks to trace information between work products. Based on these tasks, a graphical representation was set up to show how traceability is generated between the various work products of CSiT. Only a few adjustments were made to the tasks of ISO 29110 to better reflect the context of CSiT:

- Traceability between unit tests and detailed design elements has been added.

- Traceability between the detailed design and architecture document has been defined as optional. This customization does not cause any problem for compliance with ISO 29110 since this type of traceability is not mentioned.

- Names of ISO 29110 documents have been adapted to fit documents' titles used by CSiT.

\subsection{Definition of a Supplier Management Process}

Since CSiT is a system integrator, the company uses suppliers for the purchase and development of components that will be used in a product. Therefore, it was imperative for CSiT to establish a supplier management process that defines how to work with them and to reduce project risks. The SE Basic profile has only a few tasks about the 'make or buy' decisions and follow-up actions (e.g. document, review and issue a purchase order). Unfortunately, the current version of the SE Basic profile does not describe a supplier management process. This process will be included in the Intermediate and Advanced profiles. The CMMI ${ }^{\circledR}$ for Development has been consulted, as well as ISO/IEC/IEEE 15288, the INCOSE SE Handbook [21] and the PMBOK $^{\circledR}$ Guide [22]. The documentation of this process led to the creation of additional templates: request for proposal, supplier selection matrix, purchase order and purchase agreement. Also, three new sections have been added to the project plan of the SE ISO 29110 Basic profile: a list of acquisitions and potential suppliers, an acquisition plan/strategy, and a supplier management plan.

\section{Coverage between Frameworks}

As mentioned earlier, the goal of the process project was to implement the SE Basic profile of the ISO 29110 and to complement it with CMMI level 2 requirements. In order to determine the achievement of this objective, an analysis of the coverage of CSiT processes was performed. This analysis was done in two stages. First, the correspondences between the CSiT processes with ISO 29110 have been defined. Then, connections between the processes of CSiT and those of CMMI were defined.

An analysis confirmed that the processes of CSiT fully cover the objectives and tasks of the processes defined in the Basic profile. During this analysis, mappings and tailoring have been documented. This documentation also explains the tailoring decisions of CSiT.

The mapping of CSiT processes with CMMI-DEV level 2 process areas, illustrated in table 4, revealed that many of the generic practices and specific practices are covered. However, some practices still remain to be implemented or improved.

\begin{tabular}{|l|c|}
\hline CMMI-DEV Level 2 - Process Areas & Percentage of Coverage \\
\hline Configuration Management & $50-70 \%$ \\
\hline Measurement and Analysis & $20-40 \%$ \\
\hline Project Monitoring and Control & $70-90 \%$ \\
\hline Project Planning & $70-90 \%$ \\
\hline Process and Product Quality Assurance & $45-65 \%$ \\
\hline Requirements Management & $90-100 \%$ \\
\hline Supplier Agreement Management & $70-90 \%$ \\
\hline
\end{tabular}

Table 4. Approximate coverage of CSiT processes to CMMI-DEV

An analysis of the coverage of CSiT processes with CMMI-DEV level 3 process areas has also been completed. 


\section{Benefits for the VSE}

Two categories of benefits were observed by CSiT: observable benefits in day-to-day project activities and benefits to the VSE as a business. The day-to-day benefits to the VSE are:

- Standardized work and consistent deliverables across projects

- Avoids reinventing the wheel for each project

- Work is done in a systematic and disciplined way

- Better quality of deliverables and products

- Better project management and project monitoring

- Reduction of project risks

- Better communication within the team because the semantic of communication is standardized

CSiT obtained the following business benefits as a result of the of their effort to define and improve their processes:

- Better credibility to bid on tenders

- Access to markets that require certification of a quality system in line with the business practices of the company

- Better recognition of the quality of work done and products developed

- Better trust from customers and business partners

- An important step towards a maturity level of the CMMI (a CMMI level is a requirement of some customers)

\section{$7 \quad$ Implementation of ISO 29110 and Self-Assessment and Audit}

In 2012, CSiT started the development of a product suite called 'TRANSIS'. TRANSIS is a multimodal information data integration system with interactive extensions for operators and users of public transport. This project was intended to apply the processes and adjust them if necessary, ensuring a gradual adoption of the new work methods. CSiT has tested the degree of implementation of its processes in the TRANSIS project. To do this, the self-assessment score sheet of ISO 29110 was used. This score sheet was used to indicate the activities, tasks and documents produced during a project and determine the level of compliance with the standard. At the middle of the project, an assessment showed that most of the project management and system development tasks have been executed. The tasks that have not yet been covered will be executed in subsequent phases of the TRANSIS project. Recently, the processes of CSiT, based on the Basic Profile of the ISO 29110, have been successfully audited by a third-party audit composed of 2 independent auditors. One member of the audit team was a systems engineering domain expert.

\section{$8 \quad$ Recommendations}

Resulting from the development and implementation of project management and system engineering processes at CSiT, a set of recommendations was developed to help VSEs in implementing ISO 29110. Table 5 describes our mains recommendations.

\begin{tabular}{|l|l|}
\hline Recommendation & Description \\
\hline $\begin{array}{l}\text { Define the vision and objec- } \\
\text { tives of a process improvement } \\
\text { project }\end{array}$ & $\begin{array}{l}\text { A clear definition of the business motivations and objectives of the initia- } \\
\text { tive will help define the scope of the improvement project. }\end{array}$ \\
\hline $\begin{array}{l}\text { Choose a framework that meets } \\
\text { the needs of the VSE }\end{array}$ & $\begin{array}{l}\text { With clear and ideally quantified objectives, it will be possible to deter- } \\
\text { mine whether the expected results have been met. }\end{array}$ \\
\hline $\begin{array}{l}\text { Adapt the framework selected } \\
\text { to the context of the VSE }\end{array}$ & $\begin{array}{l}\text { VSEs should take the time to choose the profile that best meets their organ- } \\
\text { ization. As described in Table 1, a VSE could implement the Entry profile } \\
\text { for small projects and the Basic profile for its bigger projects. }\end{array}$ \\
\hline
\end{tabular}




\begin{tabular}{|l|l|}
\hline $\begin{array}{l}\text { Document all processes in a } \\
\text { graphical notation first }\end{array}$ & $\begin{array}{l}\text { ISO 29110 being a generic framework, it is important to do some adapta- } \\
\text { tions (e.g. terminology), while remaining consistent with the selected } \\
\text { framework. }\end{array}$ \\
\hline $\begin{array}{l}\text { Define the structure of the pro- } \\
\text { ject directories or project repos- } \\
\text { itories }\end{array}$ & $\begin{array}{l}\text { This approach helps to get the big picture of the processes and their inter- } \\
\text { actions. It enables the team to use and apply these processes faster in a } \\
\text { pilot project. It also helps to determine whether the activities and tasks } \\
\text { defined in the process are relevant and if some are missing. }\end{array}$ \\
\hline $\begin{array}{l}\text { Define a generic template for } \\
\text { documents }\end{array}$ & $\begin{array}{l}\text { A VSE should adopt a uniform directory structure from one project to an- } \\
\text { other. In this way, it is easy to navigate and work more efficiently. }\end{array}$ \\
\hline Group documents as required & $\begin{array}{l}\text { Having a generic template saves time when creating a template for a par- } \\
\text { ticular document or a project having specific needs. }\end{array}$ \\
\hline $\begin{array}{l}\text { Define the verification, valida- } \\
\text { tion and acceptance of docu- } \\
\text { ments and product elements }\end{array}$ & $\begin{array}{l}\text { The SE Basic profile lists work products in a table for presentation purpos- } \\
\text { es only. The work products may be combined by a VSE to meet the needs } \\
\text { of a project. }\end{array}$ \\
\hline $\begin{array}{l}\text { Develop and use checklists } \\
\text { Grouping documents minimizes the number of manipulations (e.g. draft- } \\
\text { ing, reviewing, approving) and the number of documents managed and } \\
\text { stored. }\end{array}$ \\
\hline $\begin{array}{l}\text { Define a minimal set of } \\
\text { measures }\end{array}$ & $\begin{array}{l}\text { A good way to facilitate the documentation process is to define the verifi- } \\
\text { cation, validation and acceptance criteria that applies to each output and } \\
\text { each deliverable. }\end{array}$ \\
\hline Conduct a pilot project & $\begin{array}{l}\text { Once completed, this table presents a clear picture of the quality control } \\
\text { and acceptance activities that must be performed during a project. }\end{array}$ \\
\hline
\end{tabular}

Table 5. Main recommendations for VSEs

\section{Conclusion}

This article has presented the development and the implementation of management and engineering processes at CSiT using the recently published the ISO 29110 for systems engineering. The ISO 29110 has greatly facilitated this work because it describes in details the processes that must be documented and implemented. It was easy for CSiT to adapt the ISO 29110 to its business context. ISO 29110 helped implementing lightweight processes. This way CSiT remains a flexible organization. ISO 29110 helped raise the organization's maturity by using industry-recognized practices that are consistent from project to project. It can be said that ISO 29110 is simple to understand and use. It is a good starting point for a VSE that also wants to cover CMMI-DEV Level 2 and 3 practices. ISO 29110 enables VSEs, such as CSiT, to become more mature more rapidly by adopting systematic, disciplined and quantifiable methods of work, which are typical of engineering environments.

\section{REFERENCES}

1. Software Engineering Institute, CMMI for Development, Version 1.3, Pittsburgh, PA: Carnegie Mellon University, CMU/SEI2010-TR-033, 2010

2. ISO/IEC TR 29110-1:2016 - Systems and software engineering -Lifecycle profiles for Very Small Entities (VSES) - Part 1: Overview, ISO, Geneva, 2016. Available at no cost from ISO: http://standards.iso.org/ittf/PubliclyAvailableStandards/index.html

3. Larrucea, X., O'Connor, R.V., Colomo-Palacios, R., Laporte, C.Y.: Software process improvement in very small organizations. IEEE Softw. 33(2), 85-89 (2016).

4. Laporte, C.Y., Hébert, C., Mineau, C., Development of a Social Network Website Using the New ISO/IEC 29110 Standard Developed Specifically for Very Small Entities, Software Quality Professional Journal, ASQ, vol. 16, no. 4, 2014, pp. 4-25. 
5. Garcia, L., Laporte, C.Y., Arteaga, J., Bruggmann, M., Implementation and Certification of ISO/IEC 29110 in an IT Startup in Peru, Software Quality Professional Journal, ASQ, vol. 17, no. 2, 2015, pp 16-29.

6. Jeljeli, H., Laporte, C.Y., Mise en oeuvre de processus logiciels à l'aide de la norme ISO/CEI 29110 dans une grande entreprise et dans un start-up, Génie logiciel, Numéro 117, June 2016 (in French).

7. Plante, F., Développement et mise en oeuvre d'un processus de type agile au sein de la direction solution trésorerie du mouvement Desjardins, Rapport de projet de maitrise, École de technologie supérieure, April 2015 (in French).

8. Lebel, K., Développement, en mode Agile, d'une application à l'aide de la norme ISO/CEI 29110 au sein du département solutions mobilité et géoréférencées d'Hydro-Québec, École de technologie supérieure, 2016 (in French).

9. Laporte, C. Y., Chevalier, F. (2016). An Innovative Approach to the Development of Project Management Processes for SmallScale Projects in a Large Engineering Company. In K. Jakobs (Ed.), Effective Standardization Management in Corporate Settings Hershey.

10. Laporte, C.Y., Chevalier, F., An Innovative Approach to the Development of Project Management Processes for Small-scale Projects in a large Engineering Company, 25th Annual International Symposium of INCOSE, Seattle, US, July 13-16, 2015.

11. ISO/IEC TR 29110-5-1-2: 2011 - Software Engineering - Lifecycle profiles for Very Small Entities (VSES) - Part 5-1-2: Management and engineering guide: Generic profile group: Basic profile, ISO, Switzerland, 2011. Available at no cost from ISO: http://standards.iso.org/ittf/PubliclyAvailableStandards/index.html

12. ISO/IEC/IEEE 15288:2015. Systems and software engineering: system life cycle processes, 2nd ed. Geneva: International Organization for Standardization, 2015.

13. ISO/IEC/IEEE 15289:2015, Systems and software engineering - Content of systems and software life cycle process information products (Documentation), ISO, 2015.

14. ISO/IEC TR 29110-5-6-2:2014 - Systems and Software Engineering - Systems Engineering Lifecycle Profiles for Very Small Entities (VSEs) - Management and engineering guide: Generic profile group: Basic profile, ISO/IEC, Geneva, Switzerland. Available at no cost from ISO at: http://standards.iso.org/ittf/PubliclyAvailableStandards

15. Laporte, C.Y., O’Connor, R.V., Paucar, L.H.G.: The implementation of ISO/IEC 29110 software engineering standards and guides in very small entities. In: Maciaszek, L.A., Fil-ipe, J., Venkatesh, R., et al. (eds.) ENASE 2015. CCIS, vol. 599, pp. 162-179. Springer, Heidelberg (2016).

16. ISO/IEC TR 29110-5-6-1:2015 - Systems and software engineering - Lifecycle profiles for Very Small Entities (VSES) - Part 5-61: Systems engineering - Management \& engineering guide: Generic profile group: Entry Profile, ISO, Switzerland, 2015. Available at no cost from ISO: http://standards.iso.org/ittf/PubliclyAvailableStandards/index.html

17. ISO/IEC 29110 Public site, [online] available from: http://profs.logti.etsmtl.ca/claporte/English/VSE/index.html

18. Laporte, C.Y., April, A., Assurance qualité logicielle, volume 2, Processus de support. Paris: Hermes, 2011. (in French)

19. Laporte, C.Y., April, A., Software Quality Assurance, John Wiley and Sons, 2017.

20. Radice R.A., Roth N.K. et al. (1985). A Programming Process Architecture. IBM Systems Journal, 24(2), p. 79-90.

21. Systems Engineering Handbook: A Guide for System Life Cycle Processes and Activities, 4th Edition, ISBN: 978-1-118-99940-0, 304 pages, 2015

22. Project Management Institute, Project Management Body of Knowledge Guide (PMBOK Guide), fifth edition. Newtown Square, Pa.: Project Management Institute, 2013. 